\title{
RESENHA
}

\section{MAIO DE 68: A BRECHA \& VINTE ANOS DEPOIS}

Anderson Lima da Silva

Martha Coletto Costa ${ }^{2}$

Diante do cinquentenário dos acontecimentos de Maio de 1968, a editora Autonomia Literária traz uma edição brasileira inédita do clássico Maio de 68: $\mathrm{A} \mathrm{brecha}^{3}$. Referência incontornável das ciências humanas e da filosofia, esta obra singular reúne ensaios de Edgar Morin, Claude Lefort e Cornelius Castoriadis elaborados em duas temporalidades distintas e complementares: em 68, enquanto o movimento ainda se processava, depois nas décadas de 70 e 80, sob um olhar retrospectivo. Ainda sob o calor dos acontecimentos, os autores empenharam-se em elucidar os traços singulares e inovadores dos movimentos contestatórios que sacudiram a França naquele ano, ressaltando o alcance de suas múltiplas significações e os seus impactos sobre as categorias tradicionais do pensamento social e político moderno. Esta mesma postura inspirada numa análise crítica do presente é encontrada em seus escritos subsequentes, que abrem distintas janelas para a reflexão de Maio de 68 em suas decorrências, ambiguidades, potencialidades e carências.

Embora cada um dos pensadores adote perspectivas e ênfases diferentes em seus ensaios, sobressai, no conjunto da obra, uma postura intelectual comum, que merece destaque. De um lado, Morin, Lefort e Castoriadis recusam-se a fazer o inventário das razões, necessárias ou acidentais, que explicariam o Maio francês; de outro, evitam enquadrá-lo em esquemas explicativos prévios e consagrados, ainda que, especialmente no caso de Castoriadis e Lefort, sejam visíveis as marcas de suas reflexões sobre o fenômeno burocrático, elaboradas uma década antes, no âmbito do grupo Socialismo ou Barbárie. Logo de início, chama a atenção o exercício intelectual a que os autores se entregam: tomam a efervescência de Maio de 68 como um acontecimento, que nasce e vive da surpresa, abrindo, em sua irrupção, um campo

\footnotetext{
${ }^{1}$ Doutorando em filosofia pela FFLCH-USP

2 Doutoranda em filosofia pela FFLCH-USP.

${ }^{3}$ LEFORT, C / CASTORIADIS, C / MORIN, E - Maio de 68 - A brecha. São Paulo: Autonomia Literária, 2018, 288p.
} 
indeterminado de possíveis. Assim, suas interpretações se elaboram assumindo a postura de "dar livre curso ao espanto", deixando-se tocar e modificar pela originalidade do acontecimento histórico sem, entretanto, abdicar do questionamento crítico e de uma perspectiva de transformação que tem em seu horizonte a abertura para outras formas de vida coletiva.

Os escritos de Morin reunidos em $A$ brecha se destacam, antes de tudo, por sua envergadura e tenacidade. Além dos textos redigidos entre maio e junho de 1968, Morin oferece um dos primeiros e mais lúcidos "balanços” de Maio de 68: em 1978, dez anos após os acontecimentos, portanto, Morin redige "Ma(io)s", buscando traçar as implicações políticas, os efeitos e significados das "comemorações" e das tentativas de "abolição do passado", dos discursos e interesses em campo no que toca à "apropriação" das distintas versões de Maio de 68 oferecidas à época. Em gesto análogo, publicará igualmente, em 1986, "Maio de 68: complexidade e ambiguidade". Por fim, 50 anos depois, em prefácio inédito à edição brasileira de $A$ brecha, Edgar Morin retoma este ano de 68 e sua distância histórica refletindo sobre seu envolvimento pessoal com os eventos, o contato com Claude Lefort e Cornelius Castoriadis - que redundaria justamente na publicação da primeira edição do livro , concluindo com uma reflexão sobre as aspirações encarnadas pelos jovens que conduziram o movimento.

Outra peculiaridade dos textos de Morin que merece destaque é a proximidade com a qual seguiu o desenrolar dos acontecimentos, sobretudo no que concerne ao movimento estudantil. Essa situação se explica em parte por sua inserção no campo - e no campus - que viria a se tornar o estopim do Maio francês: na primavera de 1968, Morin substitui por um curto período o sociólogo Henri Lefebvre na Universidade de Nanterre, o que lhe permite acompanhar como observador simpatizante a subida de temperatura que levaria Paris à efervescência, antes de tomar o país. Por outro lado, este ponto de vista privilegiado complementava-se ainda com a manutenção de uma coluna no jornal Le monde, o que lhe permitiu publicar, nas semanas em que os movimentos estavam em pleno curso, "A comuna estudantil" e "Uma revolução sem rosto", ambos retomados em A brecha. Esses ensaios, que permanecem referências incontornáveis aos estudiosos do período, seguem o fluxo turbilhonante dos acontecimentos, buscando extrair da massa generalizada da contestação suas dimensões e características originais, a fim de entrever suas direções possíveis.

Nesses textos, o foco de Morin encontra-se nas relações entre a juventude, que emerge como nova "força político-social" contestadora da civilização "adulta e adulterada", e a Universidade, ao mesmo tempo "O mais forte bastião da sociedade burguesa (que nela forma os seus quadros) e seu elo mais fraco, porque nela os estudantes são maioria e aí podem propagar o espírito de revolução". O pensador mostra-se particularmente sensível ao significado original da comuna estudantil, experiência de socialização juvenil, ao mesmo tempo lúdica e séria, 
que se singularizou ao realizar uma contestação radical da Universidade francesa e da forma das relações entre professores e alunos, do modo dominante de gestão e hierarquização do mundo universitário, dos métodos de seleção, da produção e da destinação dos saberes (sobretudo das ciências humanas) nas sociedades modernas avançadas. Contestação que, diferentemente de outros países que experimentaram um processo semelhante, extrapolou o universo estudantil e inspirou outras manifestações em diferentes setores de atividade, dando origem a um questionamento generalizado das diversas formas de autoridade, que corroeu as bases do poder de Estado e da empresa: "a ocupação, a profanação, a dessacralização, a dessantuarização da Sorbonne, provocaram uma vibração que se estendeu às universidades do interior, a setores inteiros da intelligentsia, da pesquisa científica, do ORTF [Office de RadioffusionTélévision Française], do cinema, dos escritores; essa mesma vibração agitou o mundo do trabalho e tudo se pôs a vibrar ao mesmo tempo".

Visto que a comuna estudantil possuía também uma dimensão política bastante acentuada, cujos efeitos transbordavam para a sociedade, ela proporcionou uma espécie de "reoperarização da classe operária pelos estudantes": estes não deixaram de lançar um incessante "chamado à classe operária para a ação revolucionária". Se, de um lado, a comuna estudantil inicia um movimento de contestação da autoridade, que se generaliza e desencadeia um dinamismo revolucionário, por outro, ela oscila entre um polo revolucionário e um polo reivindicativo, manifestando uma consciência dupla e contraditória, que se cinde entre a recusa e o desejo de integração na sociedade do bem-estar. São essas peculiaridades do movimento que turvam "o rosto de uma revolução que não sabe quem ela é e se ela é uma revolução". Apesar de suas carências originais (por exemplo, Morin fala "de uma falta de liberalismo" no libertarismo do movimento - expressão vaga e enigmática, note-se de passagem), o importante, a seu ver, é que o movimento conseguiu esboçar a imagem de uma sociedade e uma Universidade outras: "uma sociedade-Universidade aberta, onde a educação deve ser oferecida a todos, onde deve reinar a imaginação, não a triste burocracia, donde deve ser extirpada não somente a exploração econômica, mas também a raiz hierárquica da dominação".

Por fim, Morin ressalta o embate interno ao movimento, àquela altura ainda indefinido, entre as forças revolucionárias (simbolizadas pelo 22 de Março) e as forças políticas tradicionais (principalmente a CGT), que visavam estabilizar e dominar o curso da revolta. Em sintonia com Lefort e Castoriadis, Morin não deixa de circunscrever, à sua maneira, aquilo que lhe parece uma das maiores novidades (res)surgidas em Maio de 68, a saber, a ideia contagiante da autogestão (ou cogestão), traduzindo um desejo social de participação efetiva nas esferas da vida: "a revolução é, portanto, esse socialismo dos conselhos, que o dinamismo revolucionário multiplica enquanto comitês de ação e que, se 
prosseguir, transformará em comitês de gestão. A irrupção desse comunismo gestionário na França é justamente a novidade mais formidável da conjuntura".

Fornecendo um título deliberadamente provocativo ao seu ensaio - "A desordem nova” (1968) - Claude Lefort ressalta, antes de tudo, a conquista simbólica e irreversível do movimento de Maio: este sinaliza o dilaceramento do mito da racionalidade do sistema social de então e a perda de legitimidade dos detentores do poder. Mais ainda: põe ao olhar de todos a repentina evidência "de que as grades do capitalismo têm uma brecha"; quebra a aparência de inelutabilidade e de invulnerabilidade que o estágio avançado do capitalismo industrial havia forjado para si. O movimento também difunde a apreensão de que a pretensa "organização social" cobre e mesmo engendra a desorganização, que a autoridade é acompanhada pela incompetência e que o universo das burocracias não extrai sua sobrevivência dos supostos critérios científicos ou racionais, mas, antes, da combinação entre a força policial e a resignação dos governados. A partir de 68, essa compreensão pode ser posta à prova, "fazer seu caminho na consciência do grande número" e gerar, no curso do tempo, efeitos indeterminados.

Para o filósofo, os elementos mais originais e combativos de Maio de 68 realizaram uma crítica radical dos fundamentos da ordem capitalista e burocrática, regulada por um modelo geral de organização burocrática que impõe, em todas as instituições e setores de atividade, uma divisão hierárquica entre dirigentes e executores, o monopólio da informação e da decisão por uma pequena camada dirigente, a compartimentação das atividades, a redução dos homens ao exercício de uma mera função, a sujeição de todas as atividades a normas técnicas modeladas pelo critério da suposta "eficácia". Por isso, não é acidental, aos olhos de Lefort, que a agitação tenha se desencadeado no interior de um lugar específico da sociedade a Universidade -, a partir do qual se difundiu a contestação daquilo que é essencial à forma da relação social no capitalismo-burocrático, a saber, a divisão entre dirigentes e executores, que tira sua justificativa da divisão entre competentes e incompetentes. Isto porque "a Universidade trabalha para naturalizar a divisão entre dirigentes e executores, entre os que sabem e os que não sabem, a compartimentação das atividades, a fixação de cada um em sua função, a estrita separação do público e do privado, da atividade profissional e da vida política, de tal modo que a lei do capitalismo moderno encontre a obediência em toda parte".

Lefort confere especial atenção ao novo estilo de ação e à nova linguagem política que emergem na revolta estudantil. Sem programa, sem disciplina de partido, sem objetivo definido, os estudantes irrompiam na cena pública, ou melhor, forçavam nela a abertura de um novo lugar para fazer circular as ideias, para realizar uma ação direta, performática, cuja eficácia consistiu em "emperrar um mecanismo essencial ao funcionamento do sistema social" e, com isso, expor e minar "a adesão inconsciente da massa dos estudantes e dos professores ao que fazia a realidade de sua vida cotidiana". Essa experiência extrapolou o âmbito da 
universidade, justamente porque os estudantes fizeram a demonstração prática de que os mesmos conflitos e as mesmas revoltas trabalhavam os outros setores da sociedade, haja vista a expansão do processo de burocratização para além do campo produtivo ou educacional.

Esses efeitos da ação dos estudantes somente foram possíveis porque eles "contestaram os profissionais da contestação", libertaram-se da imagem, da disciplina e da tutela da instituição partidária clássica, saíram dos caminhos trilhados pelas organizações tradicionais e foram capazes de empreender ações que impactavam a imaginação coletiva e despertavam o desejo de imitação. Vinte anos depois, na intepretação que lhe rende com mais distância no ensaio intitulado "Releitura", Lefort continua a discernir esse traço como sendo o mais original do movimento e o mais fecundo de sua herança: "a referência aos grandes princípios não basta mais; com frequência, ela parece até mesmo suspeita. A teoria enquanto tal desperta uma desconfiança análoga à que inspira a disciplina do partido. Impõe-se a ideia de que é aqui e agora, frente aos outros - em situações que geralmente fazem parte de uma encenação - que se oferecem as oportunidades da ação. Daí a prática da interpelação, da provocação (que só raramente se transformou em perseguição), cujo objetivo é fazer aparecer o que o discurso convencional dissimula e, para além disso, a crença na ordem que o sustenta".

Inventando esse novo estilo de ação, performática, profundamente enraizada num contexto específico, no aqui e agora, que decifra a política numa situação próxima, num universo cotidiano, que denuncia a opressão e a exploração no contexto em que se manifestam, que aponta "a cara da autoridade" onde quer que ela se encarne, os agitadores de Maio colaboraram para transformar o entendimento, o alcance e a temporalidade da ação política: realizaram, segundo a célebre expressão de Jacques Donzelot, a promoção do presente. Ao liberarem suas práticas da caução de uma teoria totalizante, distinguiam-se também dos militantes tradicionais, hábeis em construir grandes narrativas, discursos fechados, destinados a garantir "um domínio imaginário sobre a sociedade".

Assim, debruçando-se sobre o estilo de ação e os discursos que se manifestaram na revolta estudantil, fulcro dos demais movimentos, Lefort os interpreta sob o signo da "extrema audácia" conjugada a um senso de "realismo". Talvez um dos saldos mais importantes da experiência de Maio de 68 tenha sido nos instruir quanto a uma compreensão mais acurada do funcionamento do poder nas sociedades democráticas modernas, nas quais "a instância do poder é indelével e sua intervenção cada vez mais ampla” e, ao mesmo tempo, nos instruir quanto aos modos criativos, eficazes e realistas de atingi-lo (em vez de destruí-lo, tomá-lo ou extingui-lo). Maio tornou sensível a prática de uma oposição incessante ao poder (a permanência de uma desordem insuperável no interior do social) e colaborou para um questionamento profundo da imagem comunista da revolução. 
Dessa interpretação, Lefort buscou extrair consequências para o quadro de uma concepção mais larga da democracia moderna: para ele, as lutas revolucionárias em nossa época se desenvolverão pela iniciativa de agitadores improvisados, à margem das instituições representativas tradicionais, agitadores que "saberão apanhar uma ocasião, explorar no setor em que se encontram a revolta que a opressão burocrática suscita". A despeito da imagem de racionalidade, ordem e organização sob a qual a sociedade capitalista-burocrática se apresenta, a erupção de Maio tornou visível que essa mesma sociedade é permeada por brechas, por onde a ordem estabelecida pode ser colocada em questão e as autoridades contestadas; são as mesmas brechas por onde, eventualmente, a pressão das reivindicações pode obter reconhecimento por meio da criação de direitos. Tendo sido um desses momentos históricos privilegiados em que a experiência democrática se mostra em "estado selvagem", isto é, sob um aspecto indomesticável, Maio de 68, para Lefort, abriu um leque de novas lutas democráticas cuja fecundidade está longe de ser esgotada.

Sob a perspectiva de Castoriadis, o protagonismo dos estudantes e a conjugação de movimentos que se opunham aos signos do Poder levavam a reformular as categorias marxistas clássicas e a repensar os modos de organização, de ação política, bem como o papel do sujeito da história, o proletariado. Assinado em sua primeira edição de 1968 sob o pseudônimo de Jean-Marc Coudray, o texto de Cornelius Castoriadis foi escrito a partir de um documento mimeografado e difundido entre fins de maio e começo de junho com o título "Agir, refletir, organizar-se", o qual foi em seguida ampliado com uma análise escrita especificamente para a publicação de $A$ brecha e renomeado "A revolução antecipada". A dimensão explicitamente militante deste escrito une análise do contexto político a um corpo de proposições relativas à organização do movimento.

Um dos aspectos fundamentais da construção dessa reciprocidade concerne às implicações do que o autor considera como o espraiamento da contestação da hierarquia. Em sua originalidade e extensão, ela revelou "o conflito central em torno do qual todos os outros se ordenam", algo que excede a questão da produção e da propriedade, a saber, "o conflito entre dirigentes e executores", que encontra "sua expressão humana e política no projeto dos burocratas de transformar os homens em objetos [...] e na recusa dos homens em se deixar transformar". Em outras palavras, o que viria a se chamar de "Maio de 68" alvejava gravemente os princípios de organização próprios à "sociedade capitalista burocrática".

É a partir desta perspectiva, desta brecha, desta abertura histórica, que Castoriadis entrevê como possibilidade e como "tarefa urgente do momento" a constituição de um "movimento revolucionário de um tipo novo" e que toma forma no projeto de autogestão, isto é, na "gestão autônoma e democrática das diversas atividades pelas coletividades que as realizam". Nessa direção, encaminha-se a um conjunto de "propostas para a constituição imediata de um movimento revolucionário", nutridas pela tentativa de definição de princípios, 
de estruturas de organização do funcionamento interno e das formas de ação de uma "democracia direta a mais ampla possível".

Retomando o fio predominantemente analítico, o desdobramento do texto, que caminha pari passu com o desenrolar dos acontecimentos, ressalta e explicita as dificuldades de efetuação de tal projeto. O que leva Castoriadis a pensar os movimentos de maio e junho como uma "Revolução antecipada", que designa tanto a luta dos estudantes contra sua situação futura quanto "prefigura aquilo que deverá, aquilo que sem dúvida será um dia a revolução contra a sociedade moderna”. Na contramão de qualquer vaticínio reconfortante, esta transformação profunda poderá advir, a seu ver, somente mediante um "trabalho políticosocial permanente", cujas "modalidades, estruturas e modo de ser" dependerão da união, do empenho e, sobretudo, da criatividade dos trabalhadores intelectuais e manuais. Se a história não oferece garantias, tampouco é a longa narrativa de um destino comum: no entender de Castoriadis, ela é antes de tudo criação humana e, como tal, modificável.

"Os movimentos dos anos sessenta" é escrito em 1986 e retomado na reedição do livro de 1988. Vinte anos depois, o contexto que impregna o ar do tempo é o de denúncia de Maio de 68. Leituras como a de Gilles Lipovetsky ( $A$ era do vazio. Ensaio sobre o individualismo contemporâneo, de 1983) e as de Luc Ferry et Alain Renaut (O pensamento 68. Ensaio sobre o antibumanismo contemporâneo, de 1985) conferiam um sentido estreitamente individualista aos acontecimentos de 68. É contra esta leitura, notadamente, que Castoriadis (assim como Lefort) se posiciona ao mesmo tempo que costura algumas apreciações retrospectivas sobre o movimento.

Para Castoriadis, os comentários que procuram fiar-se à ideia de um Maio hedonista ou estritamente individualista erram o alvo ao confundir individualismo e autonomia (conceito central para o autor, sobre o qual insiste em sua dupla dimensão individual $e$ coletiva). Ele se contrapõe, por essa via, às "leituras" que obliteram o conteúdo social ou econômico das reivindicações de Maio para se concentrarem apenas naquilo que se tornaram alguns dos valores presentes em 68. Se, nos anos 80 assistia-se, com efeito, a "um novo round de burocratizaçãoprivatização-midiatização", Castoriadis identifica neste contexto menos uma decorrência dos movimentos dos anos 60 do que o signo de sua "dissolução": "o que Maio de 68 e os outros movimentos dos anos 60 mostraram foi a persistência e o poder da busca da autonomia, traduzida ao mesmo tempo pela recusa do mundo capitalista-burocrático", mais do que isso, "no movimento de Maio e por meio dele houve uma formidável ressocialização", "o desejo de uma maior liberdade para cada um e para todos. As pessoas buscavam a verdade, a justiça, a liberdade, a comunidade". Havia, portanto, “o desejo de ver realizado um estado de atividade auto-organizada coletiva e espontânea”. Em Maio de 68, conclui, partilhou-se de algo presente em 1789, 1871 e 1917, a saber, “a tentativa de fazer existirem outras possibilidades da existência humana". 
Revisitar os acontecimentos de Maio é fundamental para compreendermos o sentido das lutas que neles se inspiraram e seus desdobramentos práticos e teóricos, dentre os quais se destacam a invenção de novos modos de ação política para além dos quadros de organização e representação tradicionais (sindicatos, partidos etc.) e a reivindicação de uma potência política própria à sociedade a distância do protagonismo do Estado, o que visa assegurar a possibilidade da transformação no interior das sociedades modernas, sobretudo num cenário em que as divisas da Revolução ou da Reforma se mostram esbatidas.

A edição brasileira conta ainda com Prefácio inédito de Edgar Morin, Apresentação de Marilena Chaui, Ensaio crítico de Olgária Matos e Posfácio de Irene Cardoso. 